\title{
EMANCIPAÇÕES DISTRITAIS E O GRAU DE DESENVOLVIMENTO HUMANO MUNICIPAL EM MINAS GERAIS
}

\author{
Marcos Antônio Nunes ${ }^{1}$ \\ Carlos Lobo ${ }^{2}$ \\ Ricardo Alexandrino Garcia ${ }^{3}$
}

Resumo: Após a aprovação da Constituição Federal de 1988, verificou-se no Brasil uma forte corrida emancipacionista distrital em quase todas as unidades federativas. Em Minas Gerais foram criados mais de cem municípios. Para aferir o suposto grau de sucesso das emancipações dos municípios mineiros utilizou-se o Índice de Desenvolvimento Humano Municipal (IDH-M) referente aos anos de 2000 e 2010. No período em análise, os resultados permitiram observar que os indicadores de desenvolvimento dos municípios recém-criados não foram significativamente distintos dos municípios-mãe. Ainda que em alguns desses novos municípios tivessem experimentado queda no nível de desenvolvimento, observou-se em determinados casos melhora no IDH-M.

Palavras-chave: Emancipações distritais. Categorias municipais. Municípios mineiros. Desenvolvimento Humano. IDH.

\section{DISTRICT EMANCIPATIONS AND THE DEGREE OF MUNICIPAL HUMAN DEVELOPMENT IN MINAS GERAIS}

Abstract: After the approval of the Federal Constitution of 1988, a federal emancipationist race was verified in Brazil in almost all the federative units. In Minas Gerais, more than 100 municipalities were created. The Municipal Human Development Index (IDH-M) for the years 2000 and 2010, distributed according to geographic mesoregion, was used to measure the degree of success of the emancipations in Minas Gerais. In the reporting period, the results showed that the development indicators of the newly created municipalities were not significantly distinct from the mother cities. Although in some of these new municipalities they experienced a drop in level of development, in some cases there was an improvement in the IDH-M.

Keywords: District Emancipations. Municipal Categories. Minas Gerais municipalities. Human development. HDI.

\section{EMANCIPACIONES DE DISTRITO Y GRADO DE DESARROLLO HUMANO MUNICIPAL EN MINAS GERAIS}

Resumen: Despues de la aprovacion de la Constitucion Federal de 1988, se comprobo em el Brasil una corrida emancipadora distrital en casi todas las unidades federales. En Minas Gerais fueron más de cien municipios creados. Para evaluar el

\footnotetext{
1 Fundação João Pinheiro, Diretoria de Políticas Públicas, Belo Horizonte, Brasil, marcos.geoman@gmail.com, https://orcid.org/0000-0001-7704-363X

2 Universidade Federal de Minas Gerais, Departamento de Geografia, Belo Horizonte, Brasil, carlosfflobo@gmial.com, http://orcid.org/0000-0002-5368-8879

3 Universidade Federal de Minas Gerais, Departamento de Geografia, Belo Horizonte, Brasil, alexandrinogarcia@gmail.com, https://orcid.org/0000-0001-7144-9866
} 
grado de sucesso de las emancipaciones mineras, se utilizo Índice de Desarrollo Humano Municipal (IDH-M) relacionados a los años de 2000 y 2010, distribuidos de acuerdo a la messoregión geografica. Durante el período en cuestión, los resultados mostraron que los indicadores de desarrollo de los municipios recién creados no fueron significativamente diferentes de los municipios padres. A pesar de que algunos de estos nuevos municipios experimentaron una caída en el nivel de desarrollo, en algunos casos hubo una mejora en el. IDH-M.

Palabras clave: Emancipaciones distritales. Categorías municipales. Municipios mineros. Desarrollo humano. IDH.

\section{Introdução}

Atualmente o Brasil possui 5.570 municípios, 1.574 a mais que o número observado em 1980 (que representou um crescimento bruto de quase $40 \%$ ). Em boa medida esse surto emancipatório no país pode ser creditado à promulgação da Constituição Federal de 1988, especialmente no início dos anos 1990. Por esse motivo, foi necessária a aprovação da Emenda Constitucional 15/1996, que estabeleceu novas exigências que deveriam constar na legislação federal. Entretanto, o projeto de lei complementar que deveria estabelecer os critérios para emancipação municipal ainda não foi aprovado pelo Congresso. O que fora aprovado no Congresso não atendeu às exigências do Palácio do Planalto. Não fosse o veto da ex-presidente Dilma Rousseff ao Projeto de Lei Complementar 416/2008, cerca de duas centenas de distritos ${ }^{4}$ poderiam ter sido elevados à categoria de município no final de 2013.

Não há um consenso entre políticos e os diferentes segmentos da sociedade civil, nem mesmo dentro do ambiente acadêmico, acerca da viabilidade econômica e orçamentária de novos municípios no país, tampouco se as emancipações resultariam em melhorias qualitativas para os munícipes. Em certa medida, a análise das condições de vida nos distritos que se emanciparam durante a década de 1990, particularmente os de Minas Gerais, podem servir de parâmetro aos debates sobre a possível viabilidade na criação de novos municípios, especialmente aqueles de pequeno porte. Destarte, esse artigo pretende avaliar o grau de sucesso obtido pelo conjunto dos municípios mineiros criados após a promulgação da Constituição Federal de 1988, que serão analisados conforme os valores do IDH-M nos períodos de 2000 a 2010. Para este propósito, afim de estabelecer parâmetros de comparação, os municípios foram analisados em três categorias: $1^{\text {a}}$ ) municípios recém-criados ("filhos"), 2) municípios de origem ("mães") e municípios sem alteração territorial ("neutros").

4 "O distrito é a subdivisão do município e autoridade administrativa, judicial, fiscal e policial, além de constituir cartório. Possui como sede uma área urbana, denominada vila, e uma área rural, intitulada de povoações isoladas" (FJP, 2017). 
A hipótese que instiga a pesquisa é que os municípios recém-criados apresentaram melhorias diferenciadas quando comparados aos demais casos nos indicadores de qualidade de vida, justamente por não terem herdado nenhum ônus administrativo quando da sua instalação e que se habilitaram em contrair empréstimos financeiros para o desenvolvimento de sua infraestrutura e disponibilizar serviços essenciais à população. Acredita-se que os investimentos realizados pelas novas administrações municipais poderiam ter reflexos positivos nas condições de vida da população local.

Embora os resultados devam ser interpretados com devido cuidado, especialmente dados os limites inerentes à escala de tempo e da abrangência dos indicadores analisados, que restringem uma avaliação mais acurada nos efeitos que se processam mais a médio e longo prazos, o exercício empírico apresentado pode servir como um alerta sobre a necessidade de uma análise mais profunda e detalhada. Se o apelo à contenção de gastos públicos tem sido utilizado como justificativa inerente a uma postura "antiemancipatória", a aporia inerente ao discurso da descentralização administrativa pode ser uma armadilha sem volta. Cabe, especialmente em um contexto de crise do sistema federativo brasileiro, uma reflexão menos apaixonada, induzida por indicadores mais concretos sobre os supostos efeitos das emancipações municipais ${ }^{5}$.

\section{O IDH como indicador e instrumento de avaliação do desenvolvimento}

O processo de elaboração e difusão de indicadores, denominado por Carley (1985) de "movimento de indicadores sociais", foi resultado da grande insatisfação que se abatia nas ciências sociais a partir de meados do século $X X$. Nesse momento, uma série de instituições e organizações internacionais investiram na produção de informações que pudessem compor a base para o desenvolvimento de um amplo sistema de indicadores sociais (LOBO \& SANTOS, 2002). Uma importante característica acerca dos indicadores sociais, como apontada por Carley (1985), refere-se ao fato de que se apresentam tanto como substitutos, quanto medidas. Como substitutos, os indicadores sociais não representam a si mesmos. Ao contrário, traduzem conceitos sociais abstratos, tais como ruas seguras, qualidade

\footnotetext{
${ }^{5}$ Conforme nota técnica da Câmara dos Deputados, juridicamente é correto utilizar a expressão "criação de municípios por emancipações distritais", já que a emancipação é do distrito (SILVA, 2007). Portanto, o termo "emancipação municipal" não está em conformidade, nem tampouco a expressão é sinônima de "emancipação distrital", uma vez que o ente municipal adquiriu autonomia político-administrativa após a promulgação da Constituição Federal de 1988.
} 
de vida, taxa de analfabetismo, etc. Por outro lado, enquanto medidas, os indicadores sociais referem-se às informações que, em termos conceituais, podem ser quantificáveis. Essa dupla característica é um ponto fundamental para se entender o real significado de um indicador. Assim, como bem definiu Jannuzzi,

Um Indicador Social é uma medida em geral quantitativa dotada de significado social substantivo, usado para substituir, quantificar ou operacionalizar um conceito social abstrato, de interesse teórico (para pesquisa acadêmica) ou programático (para a formulação de políticas). É um recurso metodológico, empiricamente referido, que informa algo sobre um aspecto da realidade ou sobre mudanças que estão se processando na mesma (JANNUZZI, 2004, p. 15).

Essas dimensões, sugeridas por Jannuzzi (2004), também permitem estabelecer distinções entre as chamadas estatísticas e indicadores sociais propriamente ditos. O que difere um indicador de uma estatística social é seu valor informativo, que decorre do fato de ser empiricamente verificado como parte de um corpo teórico. Em uma perspectiva programática o indicador social também pode ser considerado como um instrumento para monitoramento e intervenção na realidade social, para fins de formulação de políticas públicas (Jannuzzi, 2004). No Brasil, sobretudo do último quarto do século passado, intensificou-se a proposição e divulgação de indicadores sociais com o objetivo de subsidiar avaliações sobre as condições de vida da população. Não obstante, toda concepção de indicadores deveria respeitar algumas propriedades desejáveis a sua aplicabilidade (JANNUZZI, 2004).

Tanto o Produto Interno Bruto (PIB) quanto outros indicadores de renda (pessoal, familiar ou domiciliar), que têm significados diferentes, eram utilizados de modo indiscriminado para a mensuração do nível do desenvolvimento socioeconômico em diversos países. Entretanto, afora essa apologia empirista e simplista, os analistas já entendiam que os indicadores de riqueza e renda não constituem uma representação adequada para medir a qualidade de vida, o próprio desenvolvimento econômico ou os diferentes tipos de desigualdades. Fato é que o crescimento do PIB e da renda nacional mascaravam as desigualdades socioeconômicas existentes nos países (STEFANI, NUNES, MATOS, 2014).

A perspectiva de Sen (2000) se opõe completamente ao enfoque que associa desenvolvimento com crescimento da renda nacional, industrialização etc. Sen (1993) acredita que o desenvolvimento deve ter como objetivo último a melhoria dos 
"tipos de vida" que os seres humanos estão vivendo. Tanto em teoria quanto na prática o desenvolvimento deve ser definido em relação àquilo que os seres humanos podem fazer ou ser. $\mathrm{O}$ autor sugere:

\begin{abstract}
Os seres humanos são agentes, beneficiários e juízes do progresso, mas também são, direta ou indiretamente, os meios primários de toda a produção. Esse duplo papel dos seres humanos dá origem à confusão entre fins e meios no planejamento e na elaboração de políticas. De fato, essa confusão pode tomar - e frequentemente toma - a forma de uma noção da produção e da prosperidade como a essência do progresso, considerando as pessoas como os meios pelos quais tal progresso na produção é obtido (ao invés de considerar a vida das pessoas como a finalidade última e tratar a produção e a prosperidade como meios, tão somente, para atingi-la) (SEN, 1993, p.313).
\end{abstract}

Destarte, iriam surgir os indicadores de qualidade de vida, em contraposição àqueles requerentes à quantidade de riqueza produzida ou renda auferida. Outros conceitos também ganharam forma, como exemplo de Desenvolvimento Humano. Mesmo que a ampliação dos critérios econômicos do progresso material, refletidos em uma massa de estatísticas disponíveis, tendam a se concentrar especificamente no melhoramento de objetos inanimados de conveniência, pudesse ser justificada, havia uma lacuna não contemplada referente aos aspectos não materiais, embora objetivos. Há um reconhecimento crescente favorável à utilização direta de indicadores da qualidade de vida, do bem-estar e das liberdades constitutivas que as vidas humanas podem trazer consigo (SEN, 2011). O PIB seria, então, paulatinamente substituído por outros indicadores sintéticos, como o IDH, que fora instituído pelo Programa das Nações Unidas para o Desenvolvimento (PNUD) em 1990, tendo como base os trabalhos de dois economistas: do paquistanês Mahbud ul Haq e do indiano Amartya Sen.

A última década do século passado representa um importante momento nas discussões acerca do desenvolvimento. Lançado em 24 de maio de 1990, pelo PNUD, os diversos Relatórios do Desenvolvimento Humano divulgaram novas bases de interpretação e novos instrumentos para a mensuração da qualidade de vida das populações. No Brasil, esses relatórios passaram a ser regularmente publicados só a partir de 1996, quando se tornaram instrumentos de grande utilização no meio acadêmico e foram bastante difundidos em veículos de comunicação. Esses trabalhos, produzidos por diversas instituições e organismos internacionais, ao ratificarem a noção de desenvolvimento humano, buscam integrar outras dimensões 
que vão além dos tradicionais indicadores do crescimento econômico. De acordo com um desses relatórios, publicado pelo PNUD em 1998,

[...] o crescimento econômico é uma condição tão necessária para o desenvolvimento humano como este é para o crescimento econômico. Mas não é uma condição suficiente: a vinculação entre os dois não é automática (RDH, 1998, p. 36).

Ainda conforme o mesmo relatório,

O conceito do desenvolvimento humano destaca os fins do desenvolvimento e do progresso, ao invés dos meios. O desenvolvimento humano engloba tanto o processo de alargamento das escolhas pessoais quanto o nível de bem-estar alcançado. O objetivo do desenvolvimento deve ser a criação de um ambiente propício para as pessoas terem uma vida longa, saudável e criativa. Apesar de parecer uma verdade pura e simples, tal premissa é esquecida quando se leva em conta apenas a acumulação de bens e riqueza $(\mathrm{RDH}, 1998$, p. 102).

O IDH possibilita classificar e comparar, ao longo do tempo, o progresso alcançado pelo conjunto populacional dos países, estados, municípios, etc. Em sua versão atual, contempla três dimensões: o nível educacional, a esperança de vida ao nascer e o PIB per capita. É calculado como sendo a média dessas medidas, padronizadas no intervalo de 0 a 1 . Com base neste indicador, nações, estados, e outras unidades territoriais passaram a ser classificados em três níveis de desenvolvimento: baixo (IDH inferior a 0,5); médio (valores entre 0,5 e 0,8); e alto (superior a 0,8). Evidentemente, outros indicadores, "inspirados" pelo IDH foram construídos visando mensurar realidades e fenômenos específicos em diferentes países, regiões, etc., propondo ampliar o número de variáveis para a formulação de novos indicadores sintéticos. Todavia, dados os propósitos desse trabalho, optou-se pela utilização do IDH-M para avaliar o grau de desenvolvimento humano alcançado pelos municípios recém-criados, tomando como base os municípios progenitores. Desta feita, o objetivo geral é avaliar o desempenho dos municípios recém-criados ("filhos") notadamente em relação aos municípios remanescentes ("mães"), e também no tocante aos que não sofreram fracionamento territorial ("neutros"). 


\section{A Constituição Federal de 1988 como mecanismo de indução à criação de municípios}

A Constituição Federal de 1988 restaurou o Estado Federal brasileiro após um longo período de regime militar, marcado por um presidencialismo autoritário que praticamente desfigurou o federalismo do país. A Carta Magna de 1988 estruturou um federalismo de equilíbrio, ao conferir autonomia aos estados federados. Tal autonomia, contudo, pressupõe uma repartição de competências administrativas, tributárias e legislativas (TORRES, 2014), o que significou, dentre outros aspectos, que os constituintes atribuíram aos estados-membros, inclusive, o poder de legislarem sobre o tema das emancipações distritais, embutida no $\S 4^{\circ}$ do Art. 18 da Constituição Federal de 1988. Como estabelece o próprio texto constitucional:

A criação, a incorporação, a fusão e o desmembramento de Municípios preservarão a continuidade e a unidade histórico-cultural do ambiente urbano, far-se-ão por lei estadual, obedecidos os requisitos previstos em lei complementar estadual, e dependerão de consulta prévia, mediante plebiscito, às populações diretamente interessadas (BRASIL, 1989, p. 19).

Esta brecha constitucional estimulou lideranças políticas distritais à corrida emancipacionista em diferentes estados da federação. Para Siqueira (2003) dois fatores político-institucionais foram determinantes para impulsionar as emancipações no Brasil naquele contexto: 1) o novo status adquirido pelos municípios, com a garantia de transferência de recursos financeiros; e 2) legislação permissiva dos estados nacionais, que facilitou as emancipações distritais através de regras facilitadoras. A combinação desses fatores foi fundamental para deflagrar o surto emancipacionista no país ${ }^{6}$.

Esse boom emancipatório propiciou uma reação política que levou o Executivo Federal a editar a Emenda no 15 de 1996, que estabeleceu novas

\footnotetext{
${ }^{6} \mathrm{O}$ fracionamento territorial de determinado município em distritos é condição sine qua non para, no futuro, eles se tornarem municípios e garantirem a sua certidão de nascimento. Daí constituir, também, uma das razões do crescimento indiscriminado do número de distritos após a Constituição de 1988, fenômeno que aconteceu em vários estados brasileiros (NUNES \& GARCIA, 2014). Anteriormente ao surto emancipacionista mineiro, foram criados inúmeros distritos no estado, com seus termos definidos em lei municipal, por meio de votação nas respectivas câmaras municipais. Deixar a condição de povoado e tornar-se distrito também tem as suas vantagens. Isto porque a localidade passa a contar com um núcleo urbano denominado Vila, deixando de ser exclusivamente área rural, o que the garante a possibilidade de receber recursos de programas governamentais restritos aos distritos, como saneamento básico, pavimentação, cartório, agências dos correios e bancárias, etc.
} 
exigências que deveriam constar na legislação federal, deixando de fora alguns distritos pleiteantes, como, por exemplo, Brejo do Amparo, atual distrito do município de Januária, em Minas Gerais (TRE-MG, 2018). Conforme o texto da própria Emenda,

A criação, a incorporação, a fusão e o desmembramento de Municípios, farse-ão por lei estadual, dentro do período determinado por lei complementar federal, e dependerão de consulta prévia, mediante plebiscito, às populações dos Municípios envolvidos, após divulgação dos Estudos de Viabilidade Municipal, apresentados e publicados na forma da lei (BRASIL, 1996).

O projeto de lei que deveria criar estes critérios não foi aprovado pelo Congresso, pois não houve consenso com o Palácio do Planalto. O veto da expresidente Dilma Rousseff ao projeto de lei que trata sobre o tema demonstra ser uma resposta ao Congresso Nacional, que deveria estabelecer critérios mais rígidos para evitar que ocorram novos surtos emancipacionistas, sobretudo os de caráter político-eleitoral. Na ocasião, o Planalto alegou a indisponibilidade de receita em contrapartida à elevação das despesas com a criação de novos municípios. A restrição tornou-se ainda maior frente à queda de arrecadação municipal com a deflagração da crise econômica global de 2008, além das medidas tomadas pelo governo federal que executou políticas econômicas anticíclicas e de desoneração tributária para estimular alguns setores produtivos e assim manter os níveis de emprego e renda. Essas medidas refletiram na arrecadação do Imposto sobre Produtos Industrializados (IPI), um dos pilares de arrecadação do Fundo de Participação dos Municípios (FPM), que é a principal receita da maioria dos municípios brasileiros.

Fato é que as autoridades do Executivo federal conheciam os reais motivos das emancipações, desde quando tramitava no Congresso Nacional o projeto da Emenda no 15. Estudo realizado junto aos municípios emancipados indicou que as principais razões para a criação de municípios eram: o descaso da administração do município de origem (54,2\% dos casos); a existência de uma forte atividade econômica local (23,6\%); a grande extensão territorial do município de origem (20,8\%); e o grande aumento da população local, apontado por 1,4\% dos municípios emancipados (BREMAEKER, 1996). As motivações, em geral, refletem os vários anseios dos munícipes residentes em inúmeras vilas dispersas pelo país. A principal razão se traduz pela omissão das prefeituras em ofertar serviços essenciais à 
população distrital: infraestrutura urbana, saneamento básico, atendimento médico, ensino básico, etc. A segunda razão, a existência de uma atividade econômica local, pode constituir a mais relevante desde que se comprovado o "descaso" do governo municipal para com o distrito onde, por ventura, esteja instalada a atividade econômica. Contudo, é importante observar que na divisão territorial as bases econômicas sejam preservadas para que as populações envolvidas não sejam prejudicadas (BARACHO, $2000)^{7}$.

O fator "distância", terceira razão elencada, exerce forte influência à medida que o poder público municipal não consegue se fazer presente na totalidade do seu território. Na região Norte do Brasil, por exemplo, estão os maiores municípios em extensão territorial, como é o caso de Altamira (PA). Nesta região é comum a distância de centenas de quilômetros entre as sedes municipais e suas respectivas vilas. Em Minas Gerais, no município de Rio Pardo de Minas, onde quatro distritos se emanciparam na década de 1990, pelo menos dois estão afastados mais de $100 \mathrm{~km}$ da sede municipal (NUNES, 2001). Dessa forma, atender às populações dos distritos mais longínquos amplia as despesas das prefeituras. $\mathrm{O}$ ex-senador Blairo Maggi defendeu as emancipações para o caso dos distritos mato-grossenses que distam mais de 400km das sedes municipais (PLENÁRIO, 2013). Cabe ainda destacar o papel do crescimento demográfico, apontado como uma das principais motivações das emancipações. É bem provável que a recorrência desse critério reside no fato de que persiste desde as legislações passadas, vis-à-vis sua relação direta com o número mínimo de eleitores.

Desde então, com o represamento das emancipações distritais por força da legislação brasileira, verifica-se em Minas Gerais uma corrida pela instalação de novos distritos. Esta motivação, todavia, está mais atrelada à garantia de instalação de infraestrutura de telefonia móvel, conforme estímulo do Programa Minas Comunica II, que propriamente para se ingressar, no futuro, à corrida emancipacionista ${ }^{8}$. Há,

\footnotetext{
7 O caso do ex-distrito de Juatuba, na Região Metropolitana de Belo Horizonte (RMBH), é elucidativo. Juatuba, desmembrado do município de Mateus Leme, seria apenas mais um município recémemancipado nos anos 1990 em Minas Gerais, não fosse a presença da Fábrica da Brahma, hoje Companhia de Bebidas das Américas (AMBEV). Destarte, muitas emancipações prejudicaram economicamente os municípios-sede, o que estimulou a lei estadual incluir a possibilidade de indenização (SHIKIDA, s.d.).

${ }^{8}$ Esta informação foi obtida diretamente com os pesquisadores responsáveis pelos limites municipais e distritais de Minas Gerais. Atribuição que pertenceu ao extinto Instituto de Geociências Aplicadas (IGA): o artigo 36 da Lei Complementar Estadual oㅜ 37, de 18 de janeiro de 1995 (MINAS GERAIS, 1995), determina que a elaboração do estudo técnico para criação de distritos é uma atribuição exclusiva do IGA: "Cabe ao IGA prover todos os estudos, perícias e trabalhos de demarcação territorial, inclusive propostas de alteração de limites intermunicipais e interdistritais para os fins desta Lei". Contudo, o IGA, posteriormente denominado Instituto de Geoinformação e Tecnologia (IGTEC),
} 
contudo, a necessidade de uma avaliação mais detalhada sobre as condições de viabilidade econômica dos distritos que postulam a emancipação, como, ainda, uma análise acerca do nível de desenvolvimento dos municípios recém-criados, que supostamente poderiam ser beneficiados com a autonomia administrativa conquistada.

\section{As emancipações distritais e o desenvolvimento humano em Minas Gerais: algumas evidências empíricas atuais}

Minas Gerais sempre teve participação relevante no conjunto das unidades político-administrativas brasileiras. Em 1872, a província de Minas Gerais abrigava 72 municípios, o que correspondia a 11,21\% do total do país. Em 1950 essa proporção era de 20,48\%. No ano 2000 o número de municípios no estado chegou a um total de 853 (o que representava $15,49 \%$ do total de municípios do país). Contudo, dadas as condições políticas e o ordenamento legal vigente, o estado experimentou alguns surtos emancipatórios (Figura 1), especialmente nos anos 1950/1960, mas também aquele referente ao observado no início dos anos 1990, efeito direto da Constituição de 1988. Desde 1990, 130 novos municípios foram instalados em Minas Gerais ${ }^{9}$. Desse total, 33 em 1993 e 97 em 1997 (Figura 2) ${ }^{10}$. Nesses dois períodos as regiões do norte/leste do estado foram aquelas em que o fenômeno emancipatório ocorreu com maior intensidade.

foi extinto no dia 15 de setembro de 2017 em decorrência da Reforma Administrativa, passando suas atribuições à Fundação João Pinheiro (FJP).

${ }^{9}$ O Município de Itaú de Minas, emancipado de Pratápolis em 1987, é um caso curioso e atípico: foi criado antes da Constituição de 1988, em 11 de setembro de 1987 (IGA; ALEMG, 1997) e instalado em 1989 (IBGE, s. d.). Razão pela qual Itaú de Minas não figurou nesta análise.

${ }^{10}$ Ao considerar que as emancipações ocorreram em sua grande maioria até 1996 (antes da Emenda Constitucional $\mathrm{n}^{0}$ 15), os períodos selecionados para a análise da evolução do IDH-M dos municípios mineiros atendem ao objetivo proposto na pesquisa. O horizonte temporal de 10 anos compreende pelo menos a dois mandatos políticos, além da possibilidade de alternância de governo, em caso de insatisfação popular com o "descaso" da administração municipal. Afinal, este foi um dos principais motivos que justificaram as emancipações ocorridas após a Constituição Federal de 1988 (NUNES, 2017). 


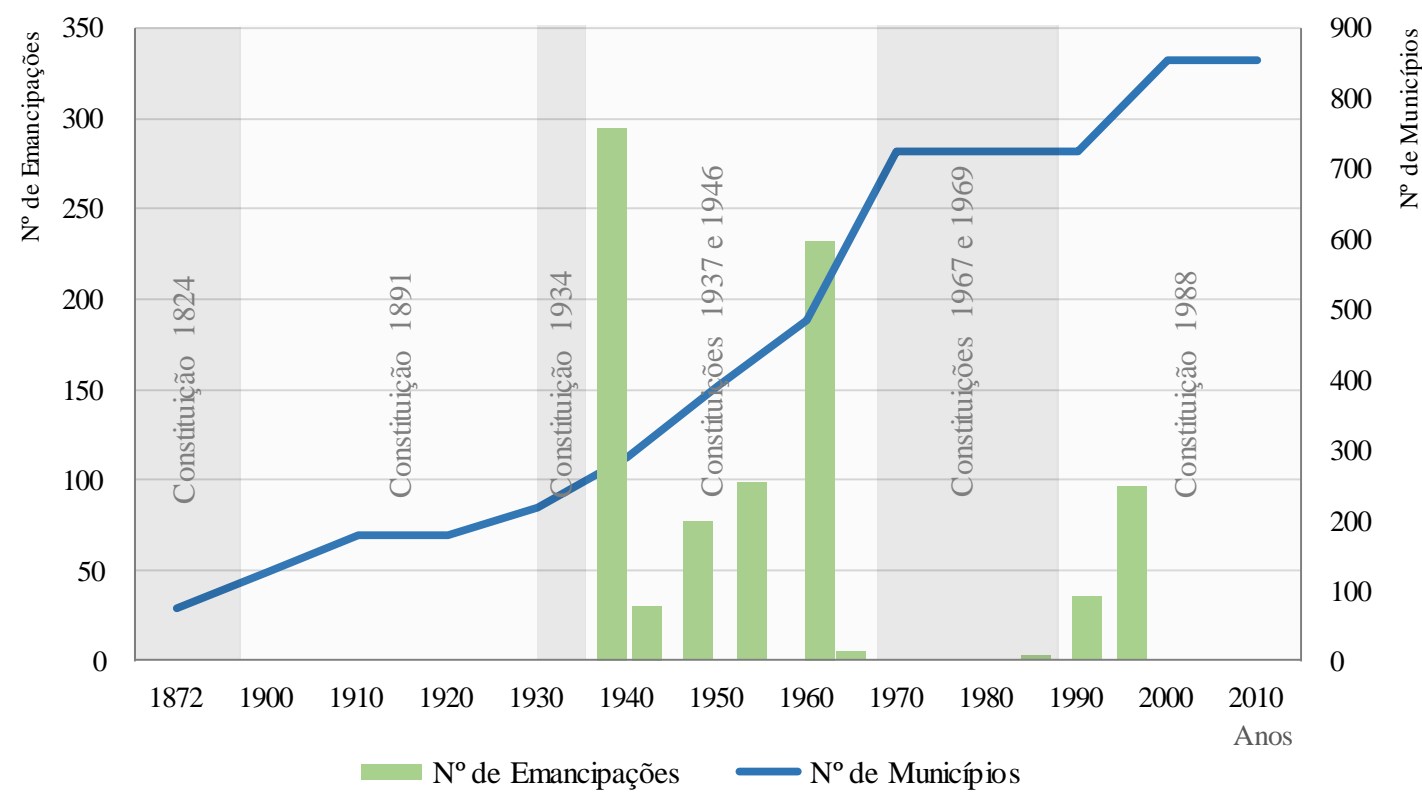

Figura 1: Evolução do número de municípios e emancipações em Minas Gerais, discriminada conforme vigências constitucionais - 1872 a 2010 Fonte: Dados extraídos de IGA e ALMG (1997)

Para analisar e avaliar o suposto grau de sucesso do desenvolvimento experimentado pelos municípios mineiros, criados após a Constituição Federal de 1988, foram estabelecidas três categorias, segundo o status do município em relação ao processo de desmembramento: municípios recém-criados ("filhos"); remanescentes de origem ("mães"); e aqueles que não sofreram fracionamento territorial ("neutros") ${ }^{11}$. A Figura 2 representa a distribuição espacial das três categorias de municípios em Minas Gerais.

\footnotetext{
11 Há casos em que o "município-mãe" gerou mais de um município - o que explica o número desta categoria ser inferior ao da categoria "filhos".
} 


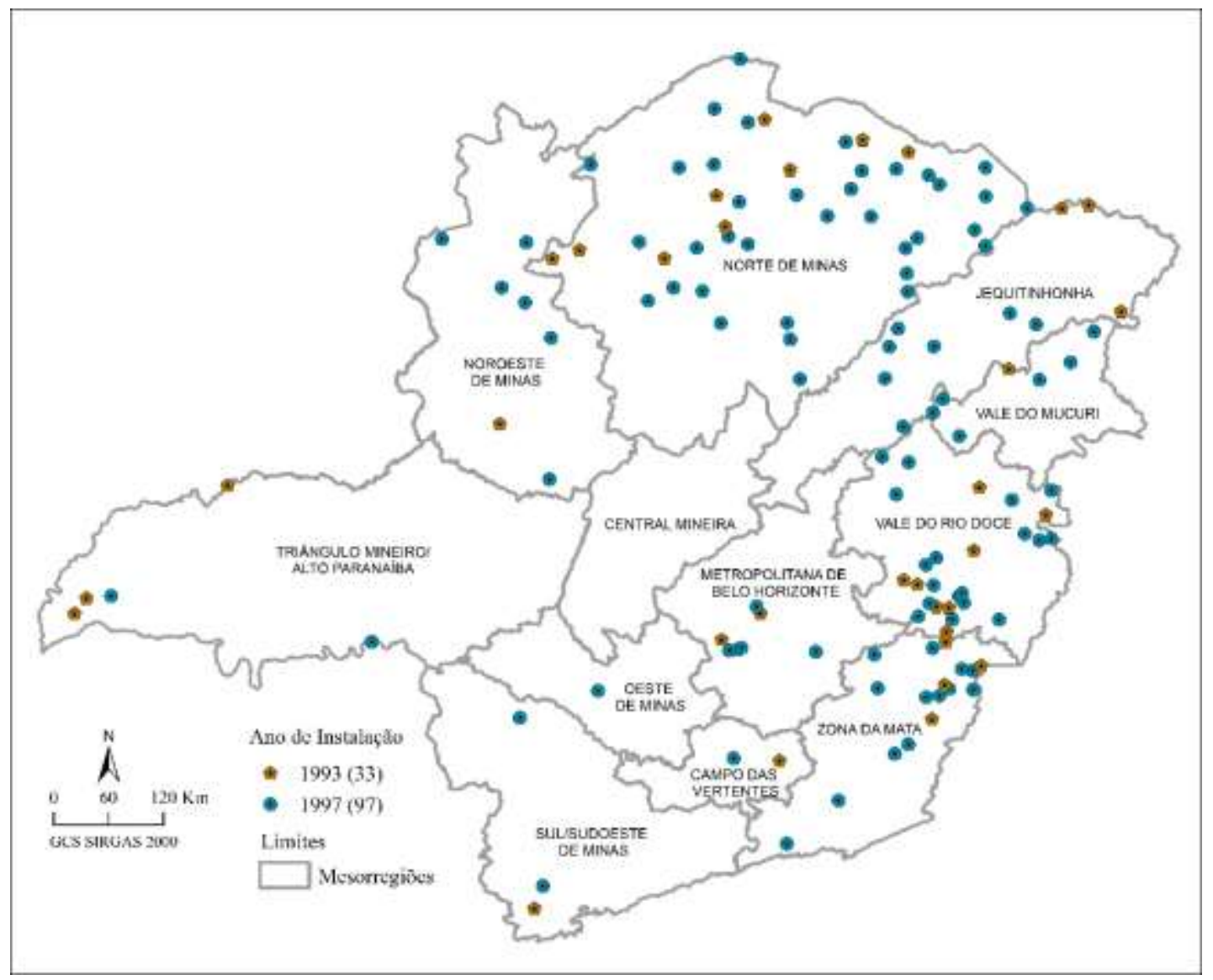

Figura 2: Sedes dos novos municípios mineiros instalados pós-Constituição de 1998 (1993 e 1997)

Fonte: Adaptado de IGA e ALMG (1997) e PNUD-Brasil (2013)

Nos últimos anos, embora o fracionamento territorial dos municípios tenha se concentrado em outros estados, as emancipações mineiras foram bastante expressivas pós-Constituição de 1988, dado que Minas Gerais é o estado mais fracionado do país, não obstante se posicionar em quarto lugar em área territorial. De acordo com dados expostos na Tabela 1, que sumarizam a distribuição regional das emancipações distritais mineiras (IGA; ALMG, 1997), nota-se que as mesorregiões mineiras que mais tiveram emancipações foram, pela ordem: a Norte de Minas, com 45 emancipações (ou 50,5\% do total de municípios daquela mesorregião); Vale do Rio Doce, onde foram criados 27 novos municípios (26,5\% do total); e Zona da Mata, com 16 municípios (11,3\% do total).

Tabela 1 - Número e percentual de municípios "filhos", "mães" e "neutros", nas mesorregiões de Minas Gerais (2010)

\begin{tabular}{l|c|c|c|c|c|c}
\hline \multirow{2}{*}{ Mesorregião } & \multicolumn{2}{|c|}{ Neutros } & \multicolumn{2}{c|}{ Mães } & \multicolumn{2}{c}{ Filhos } \\
\cline { 2 - 8 } & № & $\%$ & № & $\%$ & № & $\%$ \\
\hline Noroeste de Minas & 7 & 36,8 & 5 & 26,3 & 7 & 36,8 \\
\hline Norte de Minas & 20 & 22,5 & 24 & 27,0 & 45 & 50,5 \\
\hline
\end{tabular}




\begin{tabular}{l|cc|cc|cc}
\hline Jequitinhonha & 30 & 58,8 & 10 & 19,6 & 11 & 21,6 \\
\hline Vale do Mucuri & 12 & 52,2 & 5 & 21,7 & 6 & 26,1 \\
\hline Triângulo Mineiro e Alto Paranaíba & 58 & 87,9 & 3 & 4,6 & 5 & 7,6 \\
\hline Central Mineira & 30 & 100,0 & 0 & 0,00 & 0 & 0,0 \\
\hline Metropolitana de Belo Horizonte & 92 & 87,6 & 6 & 5,7 & 7 & 6,7 \\
\hline Vale do Rio Doce & 60 & 58,8 & 15 & 14,7 & 27 & 26,5 \\
\hline Oeste de Minas & 42 & 95,5 & 1 & 2,3 & 1 & 2,3 \\
\hline Sul e Sudoeste de Minas & 140 & 95,9 & 3 & 2,1 & 3 & 2,1 \\
\hline Campo das Vertentes & 32 & 88,9 & 2 & 5,6 & 2 & 5,6 \\
\hline Zona da Mata & 113 & 79,6 & 13 & 9,2 & 16 & 11,3 \\
\hline Total & $\mathbf{6 3 6}$ & $\mathbf{7 4 , 6}$ & $\mathbf{8 7}$ & $\mathbf{1 0 , 2}$ & $\mathbf{1 3 0}$ & $\mathbf{1 5 , 2}$ \\
\hline
\end{tabular}

Fonte: Adaptado de IGA e ALMG (1997) e PNUD-Brasil (2013).

A julgar pelo crescimento relativo do número de municípios criados em Minas Gerais, outras mesorregiões também se destacaram. Além da Mesorregião Norte de Minas e Vale do Rio Doce, as mesorregiões Noroeste de Minas, Vale do Mucuri e Jequitinhonha apresentaram, respectivamente, crescimento de 36,8\%, $26,1 \%$ e $21,6 \%$ em relação ao total de seus municípios. Todavia, as mesorregiões Norte de Minas e Vale do Rio Doce concentram mais da metade dos municípios criados após a Constituição de 1988.

De fato, conforme mostra a Figura 3, nota-se que o maior volume de emancipações ocorreu nas mesorregiões localizadas nos extremos setentrionais e na faixa leste mineira, que sempre apresentaram indicadores socioeconômicos menos favoráveis. A Figura 3 apoia nesta análise à medida que ilustra a distribuição espacial das sedes dos municípios mineiros segundo as categorias estabelecidas. Desta forma, dos 853 municípios mineiros, 636 pertencem à categoria "neutros", 87 compõem a categoria "mães" e 130 a categoria "filhos". 


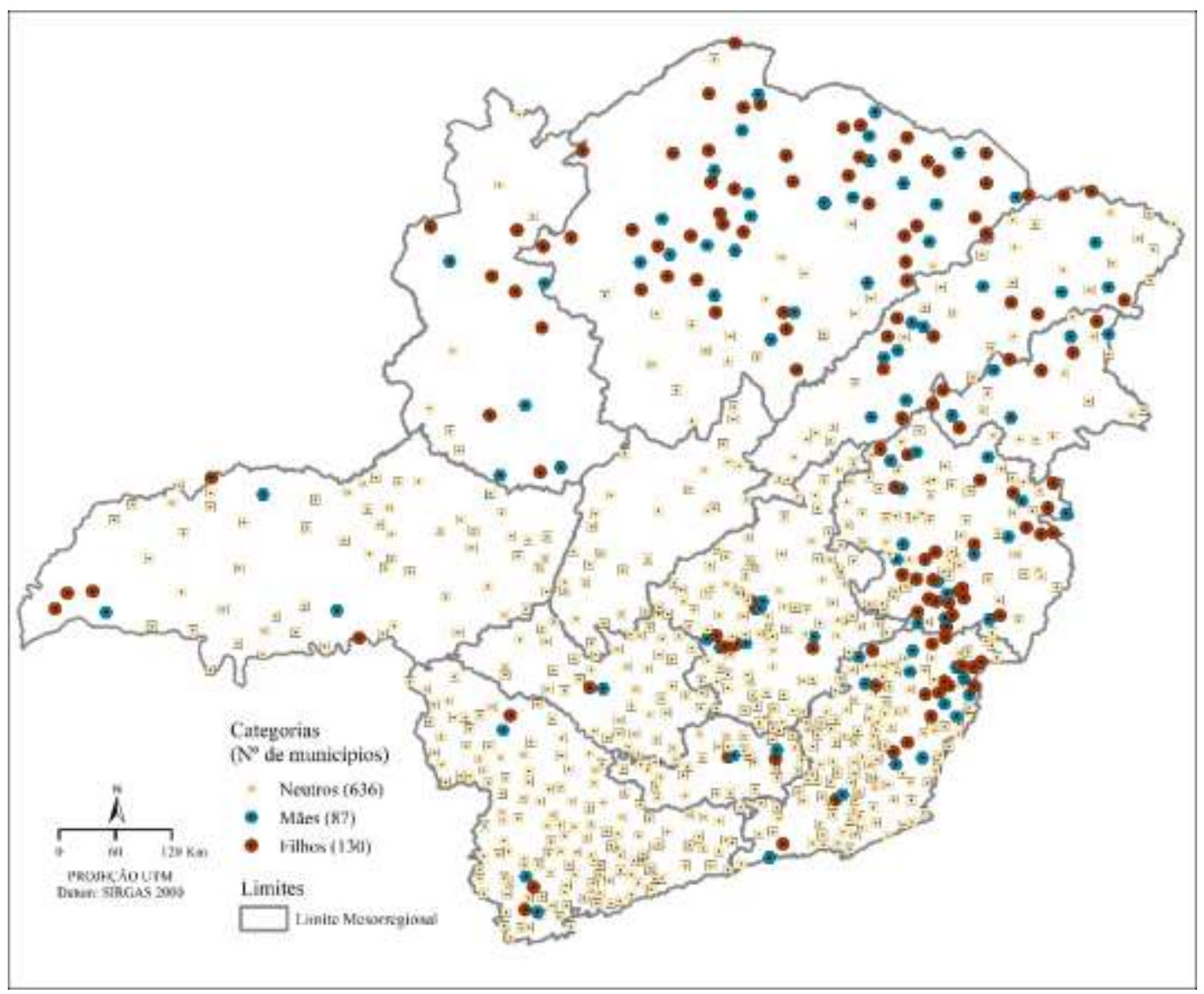

Figura 3: Distribuição espacial das sedes dos municípios mineiros, de acordo com a mesorregião e grupos: "neutros", "mães" e "filhos" - 2010 Fonte: Atlas dos Municípios (PNUD-Brasil, 2013)

Vale lembrar que, não raro, o legislativo procurou facilitar as emancipações de determinadas regiões e que, em boa parte, obteve êxito. Nunes (2001) realizou uma entrevista com o ex-deputado estadual José Braga, autor da Lei Complementar nº 37 de 1995 e do Projeto de Lei no 12.030, que se referiam à criação de municípios em Minas Gerais. De acordo com Braga, a lei foi elaborada com o objetivo de contribuir para as emancipações de distritos mais pobres da porção norte de Minas Gerais. Apesar de que outras mesorregiões, notadamente as do leste mineiro, terem alterado significativamente a geografia da organização político-administrativa estadual, não há dúvida de que a porção setentrional mineira também se beneficiou com a multiplicação do número de municípios.Paralelamente, houve um caso em que a mesorregião (Central Mineira) não sofreu nenhum fracionamento municipal após a promulgação da Constituição Federal de 1988. Em outros, o número de emancipações distritais foi reduzido. Figuram nesta lista as mesorregiões Oeste de Minas (1), Campo das Vertentes (2), Sul e Sudoeste de Minas (3) e Triângulo Mineiro e Alto Paranaíba (5). 
Em uma primeira aproximação analítica, dados os propósitos do trabalho, os resultados agregados por categorias indicam que, apesar de os municípios filhos, bem como a categoria denominada de mães, apresentarem mediana sempre abaixo do valor de referência do estado, foram aqueles que exibiram melhorias mais acentuadas nos valores do IDH-M (Figura 4). Em 2000 a mediana do IDH-M para o grupo de municípios filhos era de 0,48. Em 2010 esse índice atingiu o valor de 0,63 (bem próximo a mediana para os grupos de mães e neutros e para Minas Gerais, que era de 0,67 ).

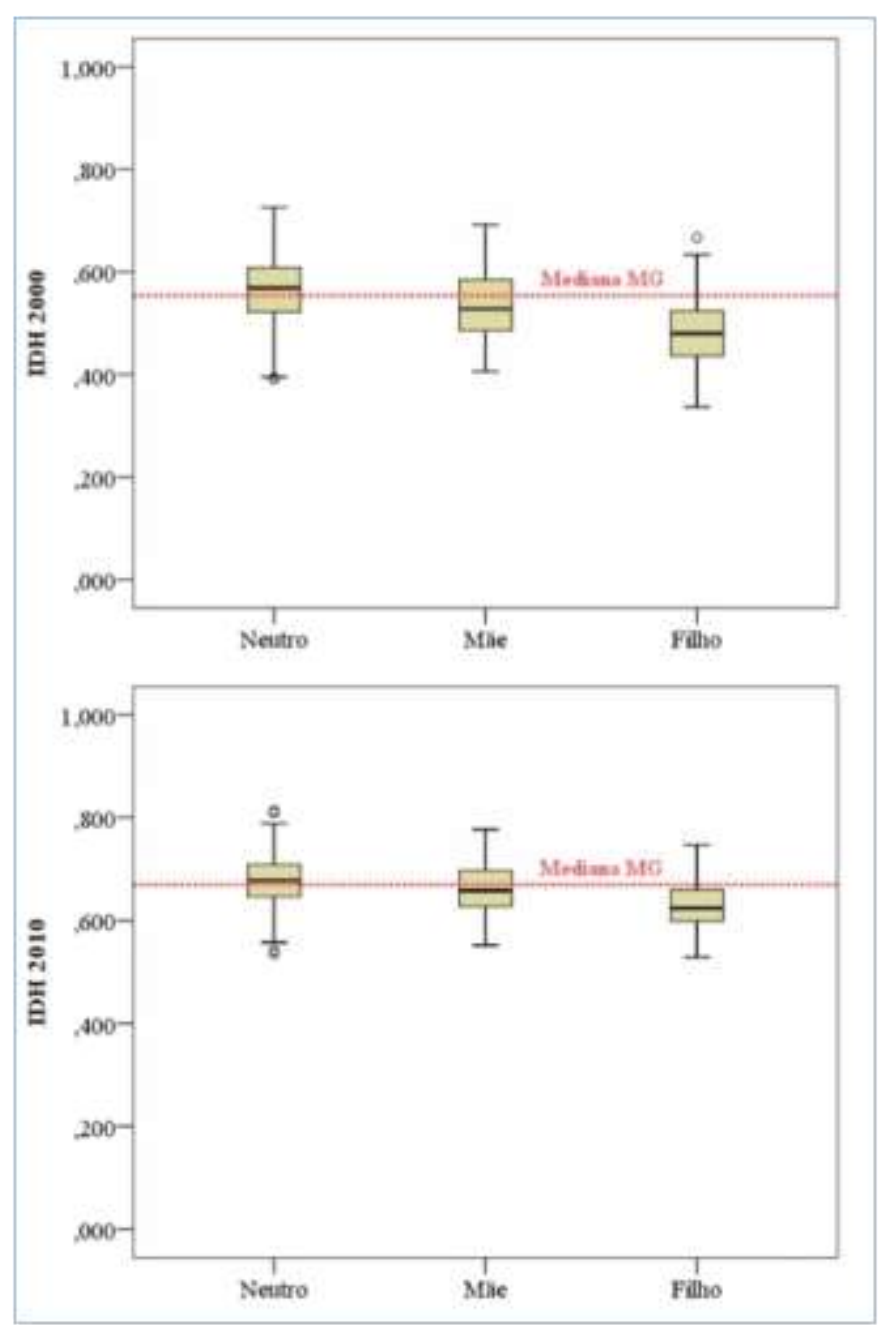

Figura 4: BOXPLOT - Mediana do IDH-M das sedes dos municípios mineiros, de acordo com categorias "neutros", "mães" e "filhos" - 2000 e 2010

Fonte: Atlas dos Municípios (PNUD-Brasil, 2013).

Essa aparente melhoria diferenciada em relação aos distritos emancipados pode, contudo, ter sido associada às tendências observadas para os munícios de origem. Soma-se a isso o fato de condições adversas ou favoráveis experimentadas por distritos emancipados serem possíveis motivadoras do processo de 
emancipação. Cabe, portanto, uma análise "genealógica" da categoria "filhos", discriminados conforme níveis de desempenho, incluindo das "mães", o que pode oferecer parâmetros adicionais. Desta forma, os municípios "filhos" e "mães" foram classificados como "bem e malsucedidos", de acordo com o sucesso no IDH-M, considerado como a variação positiva no ranqueamento conforme posição ordinal dos valores de 2000 e 2010. Aqueles que, nesse período, apresentaram melhoria relativa foram considerados "bem-sucedidos", agrupados em baixo e alto crescimento do IDH-M dos municípios de Minas Gerais (estabelecidos, respectivamente, entre a média e um desvio padrão e acima desse intervalo). Para os "malsucedidos", que exibiram piora relativa, também foram considerados os mesmos limites de baixo e alto, como estabelecidos para o grupo de "bemsucedidos".

Ao analisar o desempenho dos distritos emancipados, conforme níveis de variação do IDH-M, observou-se que 48 municípios recém-criados foram classificados "bem-sucedidos". Desse conjunto, 17 apresentaram "alto crescimento" e 31 "baixo crescimento", conforme mostra a Figura 5. Esses municípios que apresentaram variação positiva no IDH-M, correspondendo a "alto crescimento" no período, estão situados em sua maioria nas mesorregiões do Vale do Rio Doce e na Zona da Mata, que também apresentaram elevado número de emancipações.

Por seu turno, os recém-criados, que apresentaram variação negativa no IDH-M em relação aos seus progenitores, compunham a maioria dos casos, somando 82 municípios. Desse grupo, os que apresentaram "alta queda" compreendiam 42 e "baixa queda" 40. Não há, todavia, um padrão claramente definido de concentração espacial. Em geral, estão dispersos em quase todas as mesorregiões do estado, embora apareçam com maior frequência na Mesorregião Norte de Minas. Trata-se, não por coincidência, de uma região que historicamente tem experimentado condições econômicas adversas. 


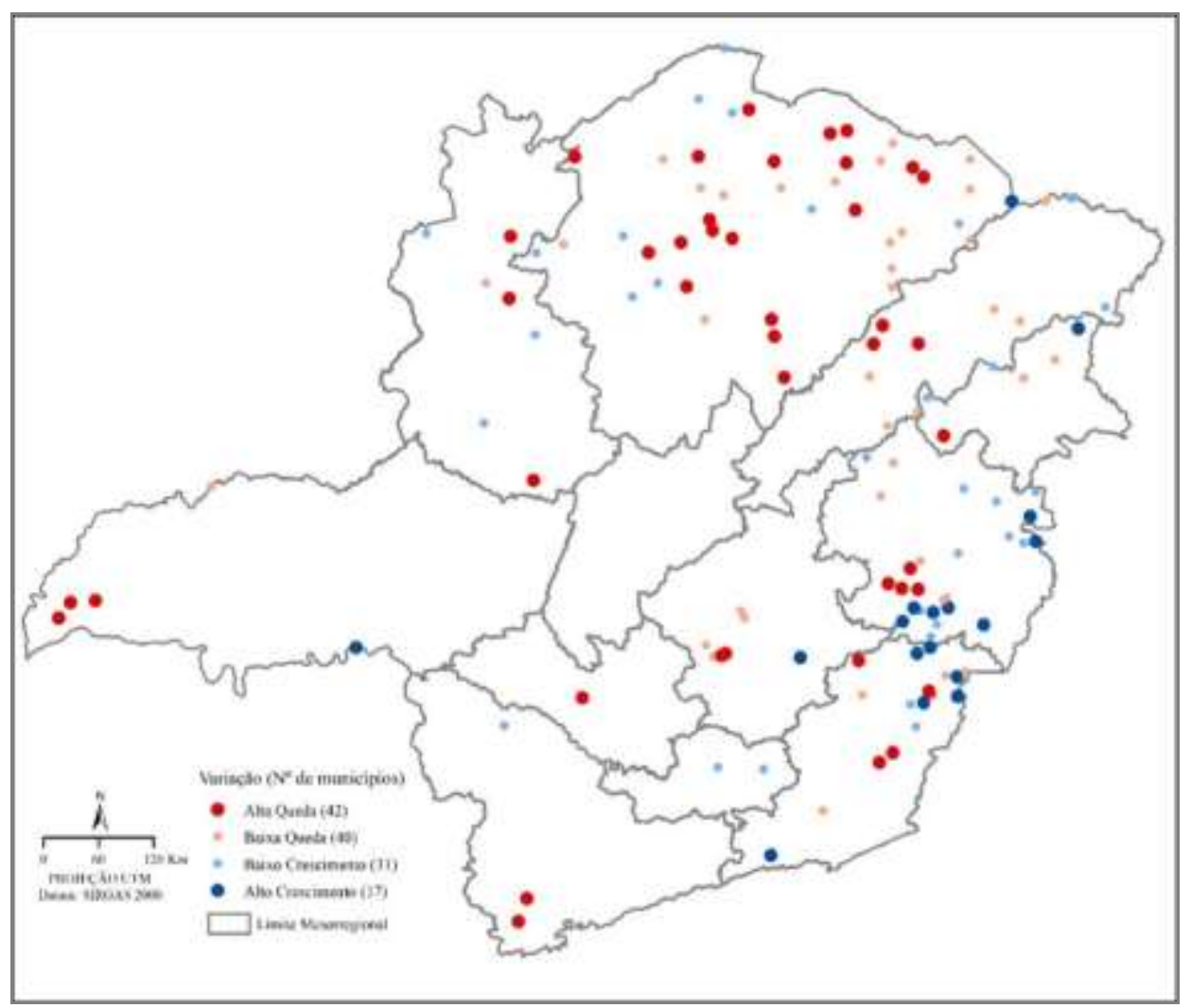

Figura 5: Distribuição dos municípios "filhos”, conforme variação do nível de desenvolvimento humano, por mesorregiões de Minas Gerais, 2010.

Fonte: Atlas dos Municípios (PNUD-Brasil, 2013).

Esses resultados iniciais induzem à formulação de algumas hipóteses. Seria o suposto insucesso emancipatório, dado pela queda considerável na posição no IDH, uma decorrência direta das condições já experimentadas pelos municípiosmãe? Haveria, portanto, uma manutenção das condições que induziriam as emancipações por condições herdadas do distrito de origem. Ou, há um número considerável de "filhos" bem-sucedidos emancipados de "mães" malsucedidas? Nesse caso, as emancipações poderiam representar formas de ruptura positiva. Uma interpretação direta dessa condição poderia considerar os efeitos positivos ou negativos de benefícios sociais e econômicos do processo de emancipação, incluindo a entrada de novos recursos orçamentários.

Ainda que a escala de tempo avaliada seja um fator limitador da análise, restringindo a interpretação dos resultados, esse exercício empírico pode suscitar alguns pontos de reflexão altamente relevantes. Os resultados representados na Figura 6 indicam que boa parte dos "filhos" malsucedidos (15 casos) foi emancipada de "mães" que apresentaram queda nas duas décadas analisadas (1991/2000 e 2000/2010). 


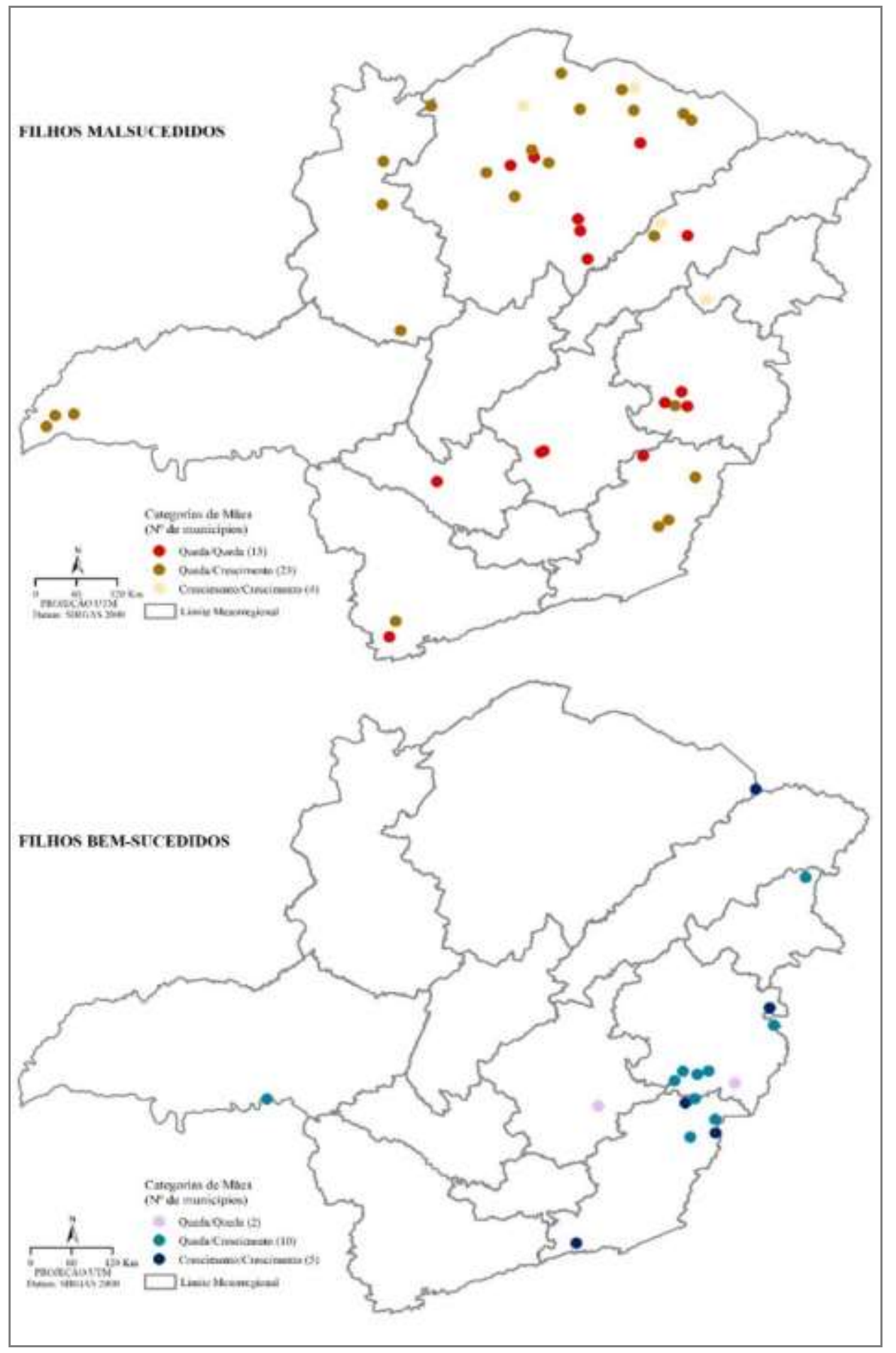

Figura 6: Distribuição dos municípios Filhos "Bem-sucedidos" e "Malsucedidos" por variação do nível de desenvolvimento humano das "Mães", por mesorregiões de Minas Gerais, 2010.

Fonte: Atlas dos Municípios (PNUD-Brasil, 2013).

\section{Considerações Finais}

Minas Gerais lidera o ranking das unidades federativas mais fracionadas do Brasil. Após a Constituição Federal de 1988, o estado registraria a criação de 130 novos municípios. Foram identificados 87 municípios que deram origem a outros, e 
636 que não sofreram fracionamento no período. Porém, após a Emenda Constitucional 15/1996, o Congresso refreou a possibilidade de novos surtos emancipacionistas no país. Apesar de ter estancado a corrida emancipacionista, já estavam criados mais de mil municípios no país. Inicialmente, a questão que se impunha era: como esses novos municípios iriam se sustentar economicamente?

A julgar pela variação positiva do IDH-M em relação aos municípios que lhes deram origem, verificou-se que parcela deles obteve êxito. Observou-se também que a maior parte das emancipações distritais mineiras ocorreu nas porções setentrionais e leste do estado. Entretanto, as que foram bem-sucedidas estão concentradas em apenas duas mesorregiões mineiras: Vale do Rio Doce e Zona da Mata; e o seu antípoda, os malsucedidos, estão concentrados na Mesorregião Norte de Minas, onde ocorreu o maior número absoluto de emancipações no estado, mas também de forma pulverizada nas demais mesorregiões.

Os resultados também apontam a necessidade de, em análises futuras, averiguar a principal causa ou conjunto de medidas adotadas pelas recentes administrações que resultaram no crescimento superior do IDH-M dos distritos novos quando confrontados aos municípios progenitores. Não se deve negar, contudo, a possibilidade de haver um padrão neste comportamento, todavia seja prudente pautar pelas especificidades, uma vez que cada localidade se difere em recursos humanos, financeiros, materiais, infraestrutura e capacidade administrativa, por exemplo. No caso dos municípios progenitores, deve-se, da mesma forma, analisar suas particularidades, situação anterior e posterior às emancipações, quantidade de distritos que se emanciparam, receita per capita antes e depois. Em suma, estão colocadas para a comunidade científica e acadêmica questões que não merecem ser ignoradas.

\section{REFERÊNCIAS}

BARACHO, M. A. P. Impactos da emancipação na arrecadação de ICMS dos municípios. Revista do Legislativo, Belo Horizonte, p. 57-66. abr./set. 2000.

BRASIL. Constituição (1988). Constituição Brasileira de 5 de outubro de 1988. Trata da organização político-administrativa da República Federativa do Brasil. In:

Constituição Brasileira 1988. Coord. José Cretella Jr. 2. ed. Rio de Janeiro: Forense Universitária, 1989.

. Constituição (1988). Emenda constitucional ํㅜ 15, de 12 de setembro de 1996. Dá nova redação ao §4ํdo art. 18 da Constituição Federal, alterando e inserindo parágrafos. Brasília, DF, 1996. Disponível em: 
<http://www.senado.gov.br/legislacao/const/con1988/CON1988_12.09.1996/art_18_. shtm>. Acesso em: 5 nov. 2013.

BREMAEKER, F. E. J. Limites à criação de novos municípios: a Emenda Constitucional no15. Revista Brasileira de Administração Pública, Rio de Janeiro, v. 43, n. 219, p. 118-128, abr./dez. 1996.

CARLEY, M. Indicadores sociais. Rio de Janeiro: Zahar, 1985.

FEIJÓ, C. A.; VALENTE, E.; CARVALHO, P. G. M. Além do PIB: uma visão crítica sobre os avanços metodológicos na mensuração do desenvolvimento socioeconômico e o debate no Brasil contemporâneo. Estatística e Sociedade, Porto Alegre, n. 2, p. 42-56, nov. 2012.

FJP - Fundação João Pinheiro. 2017. Disponível em:

<http://www.fjp.mg.gov.br/index.php/produtos-e-servicos1/3822-criacao-de-distritos>. Acesso em: 2 ago. 2017.

IBGE - INSTITUTO BRASILEIRO DE GEOGRAFIA E ESTATÍSTICA. Itaú de MinasMG. s. d. Disponível em:

<https://biblioteca.ibge.gov.br/visualizacao/dtbs/minasgerais/itaudeminas.pdf>. Acesso em: 11. Nov. 2019.

IGA - INSTITUTO DE GEOCIÊNCIAS APLICADAS; ALMG - ASSEMBLEIA LEGISLATIVA DO ESTADO DE MINAS GERAIS. As denominações urbanas de Minas Gerais: cidades e vilas mineiras com estudo toponímico e da categoria administrativa. 2. ed. Belo Horizonte: ALMG, 1997.

JANNUZZI, P. M. Indicadores sociais no Brasil: conceitos, fontes de dados e aplicações. 3. ed. Campinas-SP: Alínea, 2004.

LOBO, C. \& SANTOS, I. Desenvolvimento e qualidade de vida: a utilização de indicadores sociais. Pensar BH-Política Urbana e Ambiental, Belo Horizonte, v. 4, n. 1, p. 49-50, 2002.

MINAS GERAIS (Estado). Lei Complementar 37, de 18 de janeiro de 1995. Dispõe sobre a criação, a incorporação, a fusão e o desmembramento de municípios e dá outras providências. Minas Gerais: Assembleia Legislativa, 1995.

NUNES, M. A. Estruturação e reestruturações territoriais da região do Jequitinhonha em Minas Gerais. 2001. Dissertação (Mestrado em Geografia e Organização Humana do Espaço), Instituto de Geociências, Universidade Federal de Minas Gerais, Belo Horizonte, 2001.

Criação de municípios no Brasil: motivações, vantagens e desvantagens.

Revista Espinhaço: UFVJM, [S.I.], p. 11-20, out. 2017. Disponível em:

<http://www.revistaespinhaco.com/index.php/journal/article/view/149>. Acesso em: 24 abr. 2018.

NUNES, M. A.; GARCIA, R. A. O municipalismo brasileiro e as emancipações distritais durante a década de 1990: o grau de sucesso mediante análise do IDH. In: Simpósio Mineiro de Geografia, Alfenas, maio 2014. Disponível em: 
$<$ http://www.unifal-

mg.edu.br/simgeo/system/files/anexos/Marcos\%20Ant\%C3\%B4nio\%20Nunes.pdf>. Acesso em: 17 fev. 2020.

PLENÁRIO aprova regras para a criação de municípios. Jornal do Senado, Senado Federal, 17 out. 2013. Disponível em:

$<$ http://www12.senado.gov.br/jornal/edicoes/2013/10/17/plenario-aprova-regras-paracriacao-de-municipios>. Acesso em: 5 nov. 2013.

PNUD - Programa das Nações Unidas para o Desenvolvimento. Atlas do desenvolvimento humano no Brasil. 2013. Disponível em: <http://atlasbrasil.org.br/2013/>. Acesso em: 17 fev. 2020.

RDH - PROGRAMA DAS NAÇÕES UNIDAS PARA O DESENVOLVIMENTO. Desenvolvimento humano e condições de vida: indicadores brasileiros. Brasília, PNUD, set. 1998.

SEN, A. O desenvolvimento como expansão de capacidades. Revista Lua Nova, São Paulo, n. 27/28, p.313-333, 1993.

Desenvolvimento como liberdade. Tradução Laura Teixeira Motta. São Paulo: Companhia das Letras, 2000.

A ideia de justiça. Tradução Denise Bottmann e Ricardo Doninelli Mendes. São Paulo: Companhia das Letras, 2011.

SHIKIDA, C. D. A economia política da emancipação de municípios em Minas Gerais. Belo Horizonte, Pontifícia Universidade Católica de Minas Gerais, s.d. Disponível em: $<$ http://www3.tesouro.fazenda.gov.br/Premio_TN/iiipremio/financas/2lugar_topicos_II I_PTN/SHIKIDA_Claudio_Djissey.pdf>. Acesso em: 26 abr. 2014.

SILVA, J. A. Criação de municípios por emancipação de distritos. Brasília: Câmara dos Deputados, 2007. (Nota técnica)

SIQUEIRA, C. G. Emancipação municipal pós-Constituição de 1988: um estudo sobre o processo de criação dos novos municípios paulistas. 2003. Dissertação (Mestrado em Ciência Política). Instituto de Filosofia e Ciências Humanas, Universidade Estadual de Campinas, Campinas, 2003.

STEFANI, J.; NUNES, M. A.; MATOS, R. Índice Mineiro de Responsabilidade Social e sua dinâmica na região de planejamento Jequitinhonha/Mucuri. Caderno de Geografia, Belo Horizonte, v. 24, n. 41, p. 17-33, jan./jun., 2014.

TORRES, M. L. A divisão da competência legislativa entre os entes federados. Conteúdo Jurídico, Brasília-DF, 6 jun. 2014. Disponível em: <http://www.conteudojuridico.com.br/?artigos\&ver=2.48447\&seo=1>. Acesso em: 31 jul. 2017.

TRE-MG. Tribunal Regional Eleitoral de Minas Gerais. Plebiscitos municipais em MG - versão resumida. Disponível em: <http://www.tre-mg.jus.br/eleicoes/panorama- 
historico-das-eleicoes-em-minas-gerais/plebiscitos-municipais-em-mg-versaoresumida>. Acesso em: 11 nov. 2019.

\section{NOTAS DE AUTOR}

\section{CONTRIBUIÇÃO DE AUTORIA}

Marcos Antônio Nunes - Concepção, Metodologia, Coleta de dados, Análise de dados, Participação ativa da discussão dos resultados. Elaboração do manuscrito, revisão e aprovação da versão final do trabalho.

Carlos Lobo - Metodologia, Coleta de dados, Análise de dados, Aplicação de técnicas estatísticas, matemáticas, computacionais para analisar ou sintetizar os dados do estudo, Validação, Elaboração do manuscrito, Revisão.

Ricardo Alexandrino Garcia - Metodologia, Revisão.

\section{FINANCIAMENTO}

Não se aplica.

\section{CONSENTIMENTO DE USO DE IMAGEM}

Não se aplica.

\section{APROVAÇÃO DE COMITÊ DE ÉTICA EM PESQUISA}

Não se aplica.

\section{CONFLITO DE INTERESSES}

Não se aplica.

\section{LICENÇA DE USO}

Este artigo está licenciado sob a Licença Creative Commons CC-BY. Com essa licença você pode compartilhar, adaptar, criar para qualquer fim, desde que atribua a autoria da obra.

\section{HISTÓRICO}

Recebido em: 08-04-2019

Aprovado em: 26-12-2019 